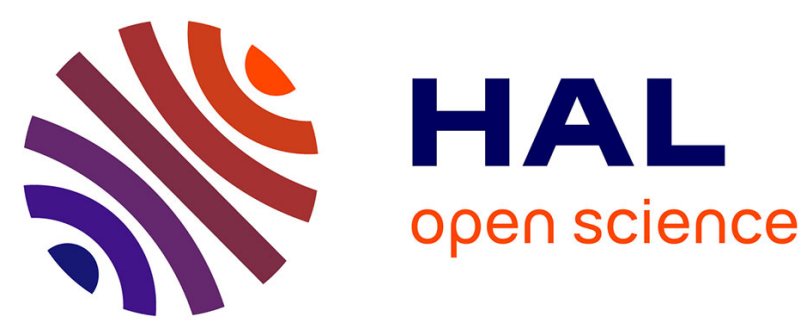

\title{
Determination of the Complete Penetration Magnetic Field of a HTS Pellet from the Measurements of the Magnetic Field at its Top-Center Surface
}

Bruno Douine, Kévin Berger, Frédéric Trillaud, Mohamed Elbaa, El Hadj Ailam

\section{To cite this version:}

Bruno Douine, Kévin Berger, Frédéric Trillaud, Mohamed Elbaa, El Hadj Ailam. Determination of the Complete Penetration Magnetic Field of a HTS Pellet from the Measurements of the Magnetic Field at its Top-Center Surface. IEEE Transactions on Applied Superconductivity, 2018, 8800104, 28 (4), 10.1109/TASC.2018.2796380 . hal-01598658v2

\section{HAL Id: hal-01598658 \\ https://hal.science/hal-01598658v2}

Submitted on 12 Jan 2018

HAL is a multi-disciplinary open access archive for the deposit and dissemination of scientific research documents, whether they are published or not. The documents may come from teaching and research institutions in France or abroad, or from public or private research centers.
L'archive ouverte pluridisciplinaire HAL, est destinée au dépôt et à la diffusion de documents scientifiques de niveau recherche, publiés ou non, émanant des établissements d'enseignement et de recherche français ou étrangers, des laboratoires publics ou privés. 


\title{
Determination of the Complete Penetration Magnetic Field of a HTS Pellet from the Measurements of the Magnetic Field at its Top-Center Surface
}

\author{
Bruno Douine, Kévin Berger, Frédéric Trillaud, Mohamed Elbaa, El Hadj Ailam
}

\begin{abstract}
In previous papers a new method to characterize HTS pellets has been presented This method is based on the measurement of their complete penetration magnetic flux density $B_{P}$. It allows determining the critical current density $J_{C}$ and the $n$ value of the classical power law model. In this paper, a method of determination of $B_{P}$ of a unique HTS pellet from the measurements of the magnetic field at its top-center surface is presented. This is a simpler and cheaper method than previous methods. It uses analytical calculation based on Biot and Savard law and numerical calculation based on power law. The maximum magnetic flux density produced by the SC pellet $B_{Z S C M}$ is deduced from the measurement. $B_{P}$ is deduced from $B_{Z S C M}$ multiplying it by a coefficient analytically calculated. The influence of $J_{C}(B)$ on this method is presented and analyzed.
\end{abstract}

Index Terms-Superconductors, magnetic field diffusion, critical current density.

\section{INTRODUCTION}

A LOT of projects of superconducting motors, generators or magnetic levitation systems have been studying on the base of high temperature superconductor (HTS) bulks because of increasing of critical current density and improvement of cryogenics [1]-[7]. The critical state model (CSM) is commonly used [8] to calculate magnetization, strength and other physical parameters. In the CSM, the current density $J$ can only be equals to 0 or the critical current density $J_{C}$ independent of the rate of variation of the externally applied magnetic field. Thanks to CSM, $J_{C}$ can be simply determined by experiments [9]-[10].

If a uniform axial magnetic field $B_{a}(t)$ is applied to a cylindrical HTS pellet, Fig. 1, the magnetic flux density at the center of the pellet $B_{0}(t)$ starts to rise after some time delay $T_{P}$, related to the moment at which $B_{a}$ reaches $B_{P}$, Fig. 2. Biot-

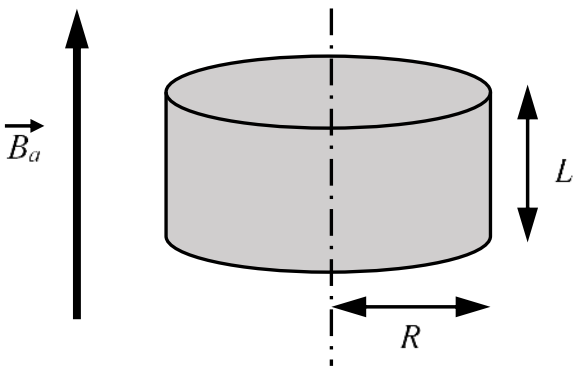

Fig. 1. Cylindrical bulk superconducting pellet submitted to a uniform axial magnetic field $B_{a}(\mathrm{t})$.

Bruno Douine and Kévin Berger are with the University of Lorraine, Groupe de Recherche en Energie Electrique de Nancy, 54506 Vandoeuvre-lès-Nancy, France (email: bruno.douine@univ-lorraine.fr, kevin.berger@univ-lorraine.fr). Frédéric Trillaud is with the Instituto de Ingeniería, Universidad Nacional Autónoma de Mexico, Mexico (email: FTrillaudP@iingen.unam.mx)
Savart law, assuming CSM with a magnetic field independent $J_{C}$, allows calculating an analytic expression for the complete penetration field, named $B_{P B}$, for cylinders, i.e. [10]-[12]:

$$
B_{P B}=\frac{\mu_{0} J_{C} \cdot L}{4} \cdot \ln \left(\frac{\sqrt{R^{2}+\left(\frac{L}{2}\right)^{2}}+R}{\sqrt{R^{2}+\left(\frac{L}{2}\right)^{2}}-R}\right)
$$

where $L$ is the length of cylinder and $R$ is its radius.

The power law model (PLM) (2) is commonly used for HTS for temperatures above $50 \mathrm{~K}$, instead of CSM [11], [12].

$$
E=E_{C}\left(\frac{J}{J_{C}}\right)^{n}=\frac{E_{C}}{J_{C}}\left(\frac{J}{J_{C}}\right)^{n-1} J
$$

The calculation of the magnetization of superconducting samples assuming PLM generally requires numerical simulations. The method of determination of the $J_{C}$ and $n$ parameters using PLM is given in [11]. It has been shown that the complete penetration magnetic field $B_{P}$ depends on the $n$ value and the applied magnetic field rising rate $V_{b}$, Fig.2:

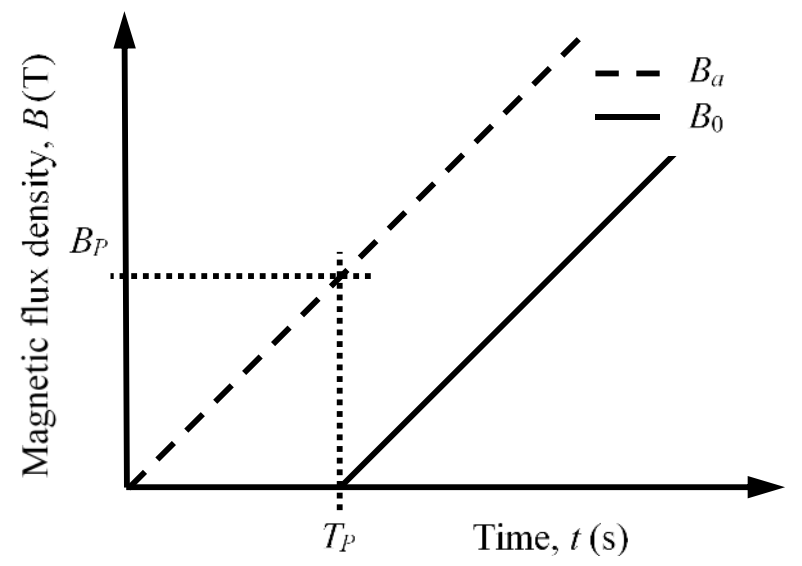

Fig. 2. Linearly growing applied magnetic field $\left(B_{a}\right)$ and theoretical magnetic field $\left(B_{0}\right)$ at the center of the pellet versus time $(t)$.

Mohamed Elbaa and El Hadj Ailam are with the Laboratoire de l'Energie et des Systèmes Intelligents, University of Khemis Miliana, Algeria (email: m.elbaa@univ-dbkm.dz, e.ailam@univ-dbkm.dz) 
$B_{P}=B_{P B}\left(1+\frac{\alpha \ln V_{b}+\beta}{n}\right)$

with $\alpha=1.2$ and $\beta=3.4$ [11].

In [12], it has been shown that there is no influence of geometrical parameters $R$ and $L$ on these values of $\alpha$ and $\beta$ for commonly used HTS pellets.

Based on (3) PLM, $J_{C}$ and $n$-value of a cylindrical sample are calculated from experimental measurements using two identical pellets, the magnetic field being measured by axial Hall probe between the two HTS pellets [11]. In this paper a method of determination of $B_{P}$ of a unique HTS pellet from the measurements of the magnetic field at its top-center surface is presented. This could be a simpler and cheaper method than the previous method using two pellets. This method uses one Hall probe placed at a distance $\mathrm{d}$ from the top-center surface of the pellet (Fig. 3). In this case the issue is to know the relationship between the measured magnetic flux density by Hall probe and $B_{P}$. From $B_{P 1}$ and $B_{P 2}$ measured at two rise rates of applied magnetic field $V_{b 1}$ and $V_{b 2}, n$-value, $B_{P B}$ and finally $J_{C}$ can be deduced [11], Fig. 4.

\section{CALCUlations OF THE RELATIONSHIP BETWEEN THE MEASURED MAGNETIC FLUX DENSITY AND $B_{P}$}

A combination of numerical simulations and analytical calculations has been used to determine the relationship between the measured magnetic flux density by Hall probe and $B_{P}$.

\section{A. Numerical simulations}

Firstly, numerical simulations of a HTS pellet $(1 \mathrm{~cm}$ radius $R$ and $1 \mathrm{~cm}$ length $L$ ) submitted to linearly rising applied magnetic field as in [11]. This allows us to determine the magnetic flux density inside and outside the HTS pellet and the current density inside the HTS pellet.

Fig. 5 represents the distributions of $J / J_{C}$ in a HTS pellet for three different $V_{b}(0.1 \mathrm{~T} / \mathrm{s}, 10 \mathrm{~T} / \mathrm{s}$ and $1000 \mathrm{~T} / \mathrm{s})$ for the same

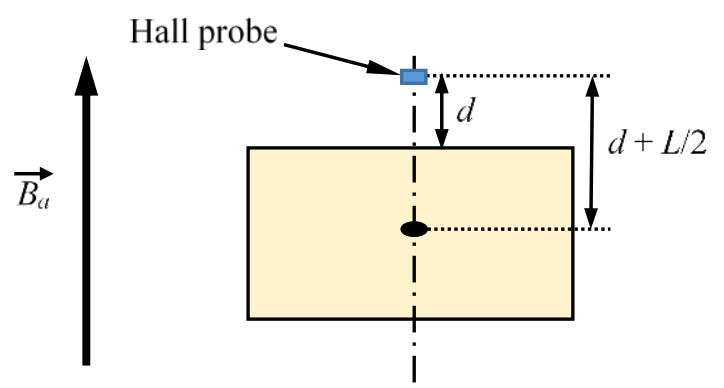

Fig. 3. Hall probe location above the HTS pellet.

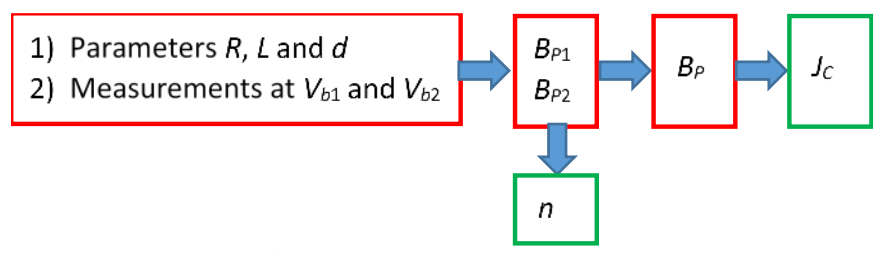

Fig. 4. Determination of $J_{C}$ and $n$-value. value of $B_{a}$. In these simulations the $n$-value chosen is 15 , that is a weak n-value for HTS at $77 \mathrm{~K}$ [11-15], $J_{C}$ is constant and equals to $100 \mathrm{~A} / \mathrm{mm}^{2}$. As shown in Fig. 5 and confirmed by other simulations, whatever $V_{b}$, geometrical parameters and sufficiently high $n$-value ( $n>10), J / J_{C}$ is almost constant all over $J$ exists. However $J / J_{C}$ depends on $n$-value and $V_{b}$ that are dynamic parameters. So in complete penetration case when $B_{a}$ equals $B_{P}, J / J_{C}$ can be considered constant all over the HTS pellet as in the case of Bean model.

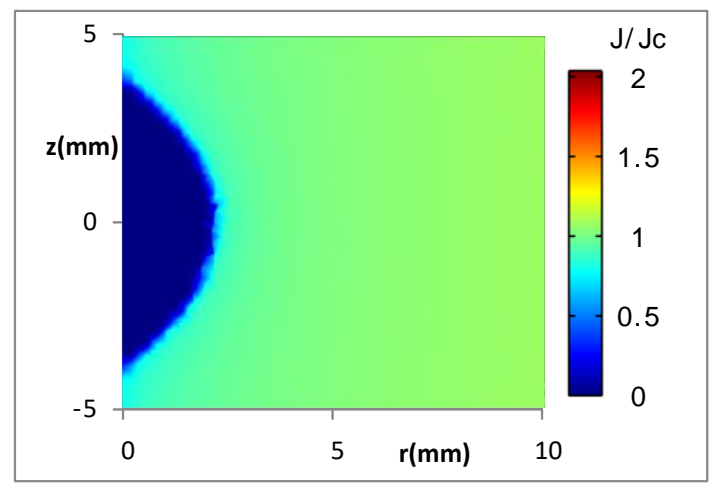

a ) $\mathrm{Vb}=0.1 \mathrm{~T} / \mathrm{s}$

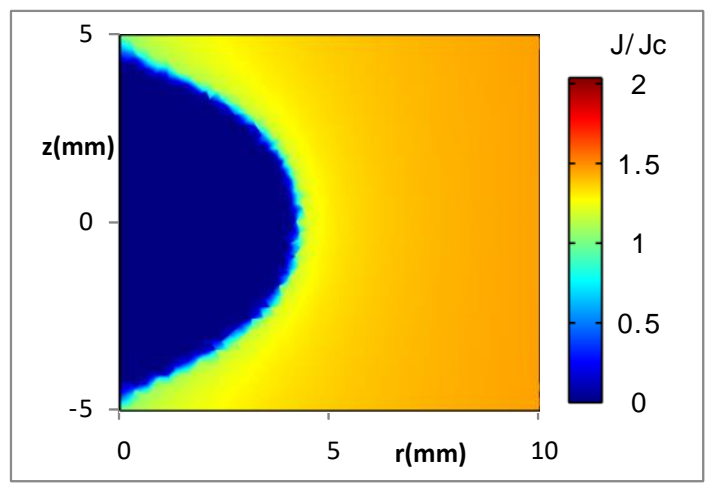

b) $\mathrm{Vb}=10 \mathrm{~T} / \mathrm{s}$

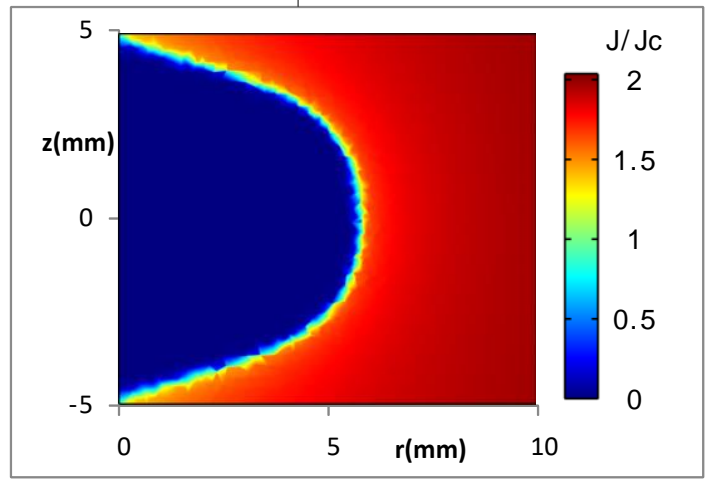

c) $\mathrm{Vb}=1000 \mathrm{~T} / \mathrm{s}$

Fig. 5. $J / J_{C}$ distributions in the pellet for different rise rates for the same applied magnetic field.

The magnetic field at the center pellet is named $B_{0}(t)$ and the magnetic field at the position of the Hall probe is named $B_{z}(d, t)$. For $n=15 B_{a}(t)$ and $B_{z}(d=0.5 \mathrm{~mm}, t)$ are represented in Fig. 6 
for constant $J_{C}$ and equals to $100 \mathrm{~A} / \mathrm{mm}^{2}$. The difference $B_{a}(t)-B_{z}(d=0.5 \mathrm{~mm}, t)$ represented in Fig. 6 is the magnetic flux density produced by the induced current inside the superconducting pellet named $B_{Z S C}(d, t)$. Fig.6 shows that $B_{Z S C}(d=0.5 \mathrm{~mm}, t)$ reaches a maximum value $B_{Z S C M}$ before $B_{a}(t)-B_{0}(t)$ reaches $B_{P}$. $B_{Z S C M}$ is directly linked to $B_{P}$ because in complete penetration case, $J / J_{C}$ is almost constant all over the HTS pellet and the HTS pellet can produce $B_{P}$ and not more $B_{P}$. The relationshipe between $B_{Z S C M}$ and $B_{P}$ is linked to geometrical parameters $R$ and like with CSM as it will be shown in part II- $B$.

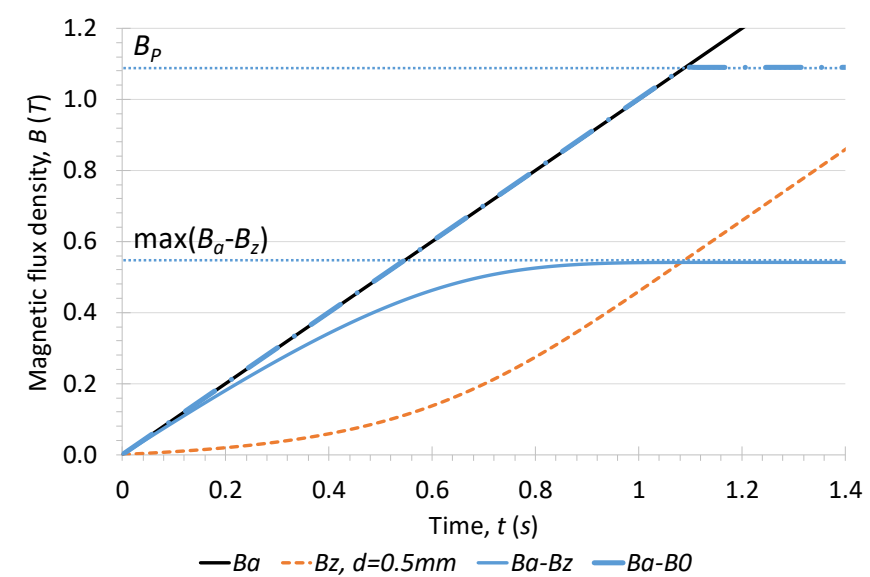

Fig. 6. Numerical calculation of $B_{a}(t)-B_{z}(d=0.5 \mathrm{~mm}, t)$ and $B_{a}(t)-B_{0}$, with $n=15, V_{b}=1 \mathrm{~T} / \mathrm{s}$.

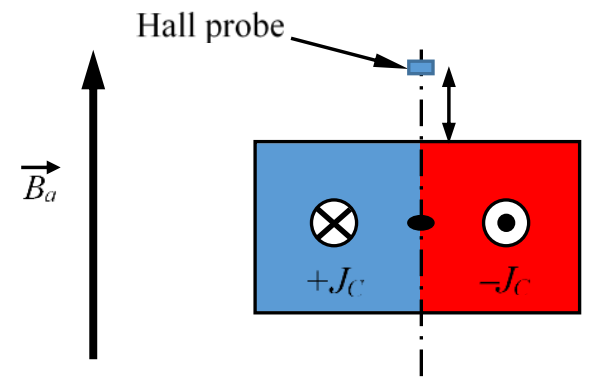

Fig. 7. Complete penetration of the current density with CSM.

\section{B. Analytical calculation of the magnetic flux density along the pellet axis}

In the case of the magnetic field complete penetration and CSM, the magnetic flux density along the axis of the cylindrical pellet $B_{Z S C B}$ can be calculated using Biot-Savart law in the same way as the $B_{P B}(1) . B_{Z S C B}$ is produced by homogenous and constant critical current $J_{C}$ in the volume of the pellet (Fig. 7).
The formula of $B_{Z S C B}$ is obviously similar to (1): $B_{Z S C B}(d, R, L)=$

$\frac{\mu_{0} . J_{C}}{4}\left[(d+L) \cdot \ln \left(\frac{1+\frac{R}{\sqrt{(d+L)^{2}+R^{2}}}}{1-\frac{R}{\sqrt{(d+L)^{2}+R^{2}}}}\right)\right]$

$$
-\frac{\mu_{0} . J_{C}}{4}\left[d \cdot \ln \left(\frac{1+\frac{R}{\sqrt{d^{2}+R^{2}}}}{1-\frac{R}{\sqrt{d^{2}+R^{2}}}}\right)\right]
$$

Fig. 8 shows $B_{Z S C B}$ versus $d$ for realistic values of $d$ due the thickness of Hall probes.

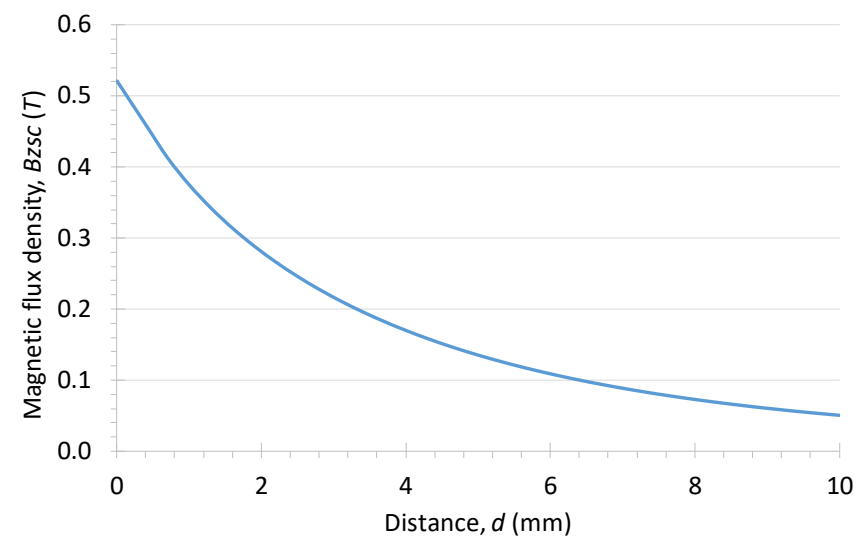

Fig. 8. Analytical calculation of $B_{Z S C}$ along the axis of the pellet in complete penetration case.

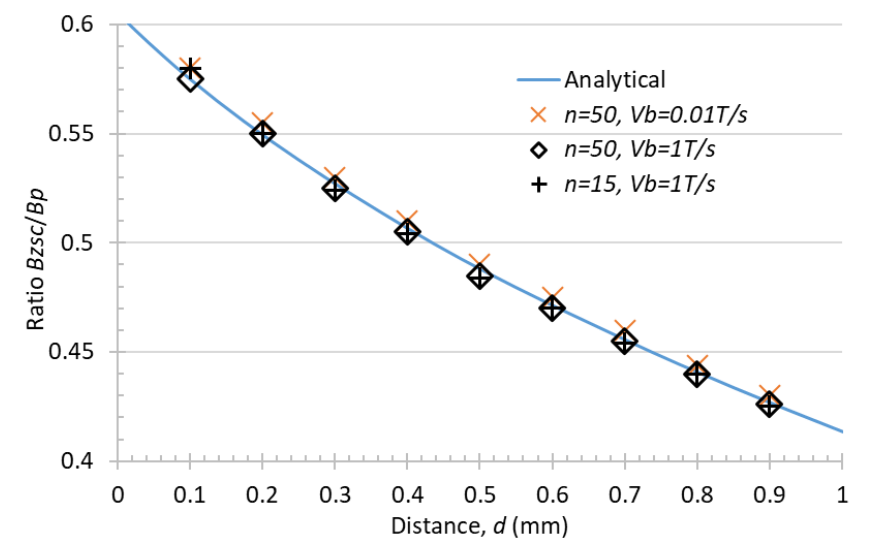

Fig. 9. Comparison of numerical calculation of $B_{Z S C M} / B_{P}$ and analytical calculation of $B_{Z S C B} / B_{P B}$.

\section{Comparison of analytical and numerical calculation of $B_{Z S C M} / B_{P}$ for complete penetration case}

The last question is to know if the numerically calculated ratio $B_{Z S C M}(d) / B_{P}$ and the analytically calculated ratio $B_{Z S C B}(d) / B_{P B}$ are equivalent or different. $B_{Z S C M}(d) / B_{P B}$ has been numerically calculated with various $n$-value from 15 to 50 and various magnetic field rise rate from $1 \mathrm{~T} / \mathrm{s}$ to $1000 \mathrm{~T} / \mathrm{s}$. Fig. 9 
clearly shows that these two ratios are equivalent for these numerous values of both these parameters. It means that $B_{Z S C B}(d) / B_{P B}$ is relevant to deduce $B_{P}$ from $B_{Z S C M}(d)$ drawn from measurement whatever $n$-value and $V_{b}$ :

$$
B_{P}=\frac{B_{Z S C M}(d)_{\text {measured }}}{\left(B_{Z S C B}(d) / B_{P B}\right)_{\text {analytical }}}
$$

It should be added that the ratio $B_{Z S C B}(d) / B_{P B}$ is $J_{C}$ independent and depends only on geometrical parameters $R$ and $L$.

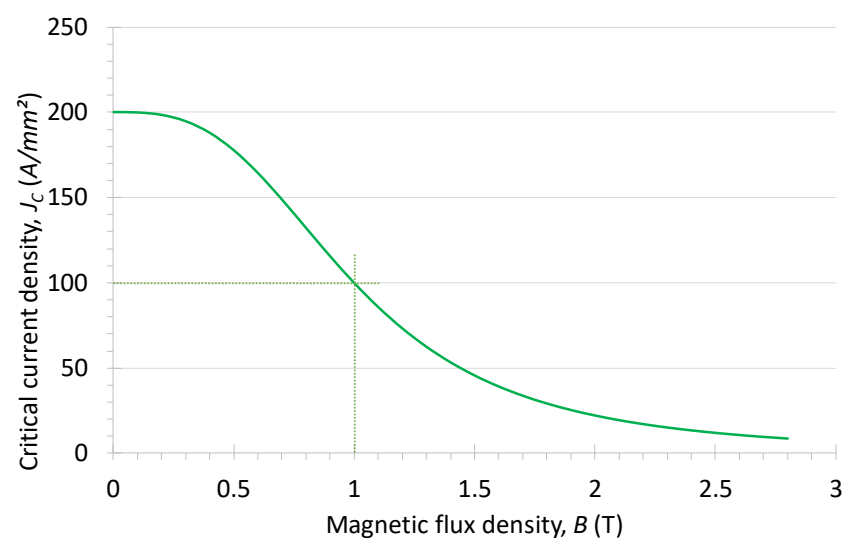

Fig. 10. $J_{C}(B)$ used in numerical simulations.

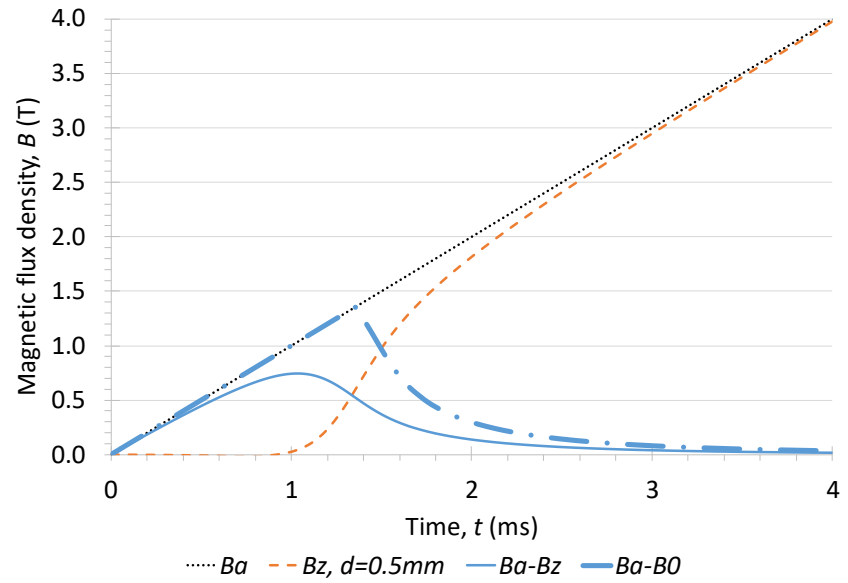

Fig. 11. Numerical calculation of $B_{a}(t)-B_{z}(d=0.5 \mathrm{~mm}, t)$ and $B_{a}(t)-B_{0}$, with $n=15, V_{b}=1 \mathrm{~T} / \mathrm{s}$ and $J_{C}(B)$.

\section{$D$. Influence of $J c(B)$ on results of this determination method}

The most important assumption made in this method is constant $J_{C}$. In this section the influence of $J_{C}(B)$ is analyzed. Numerical simulations of a HTS pellet submitted to linearly rising applied magnetic field has been made using $J_{C}(B)$ as:

$$
J c(B)=\frac{J_{C 0}}{1+\left(|B| / B_{C 0}\right)^{3}}
$$

with $J_{C O}=200 \mathrm{~A} / \mathrm{mm}^{2}$ and $B_{C 0}=1 \mathrm{~T}$.

$J_{C 0}$ and $B_{C 0}$ are arbitrarily chosen to have huge variation of $J_{C}(B)$, represented in Fig. 10, around $B_{P}=1.1 \mathrm{~T}$ which has been previously calculated with constant $J_{C}$. This numerical calculation has been made with the same dynamics parameters as those in Fig. 6, namely $n=15$ and $V_{b}=1 \mathrm{~T} / \mathrm{s}$.

The results of this simulations shown in Fig. 11 that the magnetic flux density produced by HTS pellet $B_{Z S C}(t)$ equals to $B_{a}(t)-B_{Z}(t)$ presents a unique maximum value $B_{Z S C M}$ instead of a saturation plateau as in the case of constant $J_{C}$, in Fig. 6. $B_{P}$ is the maximum value of $B_{a}(t)-B_{0}(t)$ and equals $1.35 \mathrm{~T}$, in Fig. 11 . For $d=0.5 \mathrm{~mm}$, the calculated $B_{Z S C M}$ is $0.745 \mathrm{~T}$ and it corresponds to $B_{Z S C M}(d) / B_{P}=0.55$ instead of 0.49 for constant $J_{C}$, Fig. 9. This difference is due to the non-homogeneity of the magnetic flux density and current density inside the HTS pellet. In this case (4) has to be recalculated which is not analytically possible with Biot-Savart law and can only be made by numerical simulations. This remaining work has to be done in the next step of our work.

\section{CONCLUSION}

The main idea of this paper is to determine $B_{P}$ of a unique pellet HTS pellet from the measurement of the maximum magnetic flux density at the top-center surface $B_{Z S C M}$ of this pellet. Analytical calculated ratio $B_{Z S C B}(d) / B_{P B}$ similar as numerically calculated ratio $B_{Z S C M}(d) / B_{P B}$ allows us to simply determine $B_{P}$. The influence of $J_{C}(B)$ of this $B_{P}, n$-value and $J_{C}$ determination method has to be studied further in next studies to improve the relevance of our method. The comparison of this method with previous ones [13]-[15] has to be done too.

\section{ACKNOWLEDGMENT}

This work is supported by the Hubert Curien FrenchAlgerian TASSILI program.

\section{REFERENCES}

[1] A. Rezzoug, J. Leveque, B. Douine, S. Mezani, "Superconducting machines", in Non-conventional electrical machines, Wiley, 2012, pp. 191-255.

[2] E. Ailam, D. Netter, J. Leveque, B. Douine, P. Masson, A. Rezzoug, "Design and Testing of a Superconducting Rotating Machine", IEEE Trans. on Appl. Supercond., vol.17(1), pp.27-33, 2007.

[3] R. Moulin, J. Leveque, L. Durantay, B. Douine, D. Netter, A. Rezzoug, "Superconducting Multi-Stacks Inductor for Synchronous Motors Using the Diamagnetism Property of Bulk Material, " IEEE Trans. on Industrial Electronics, vol. 57, no. 1, pp. 146-153, 2010

[4] P. Masson, M. Breschi, P. Tixador, C.A. Luongo, "Design of HTS axial flux motor aircraft propulsion", IEEE Trans. on Appl. Supercond, Vol. 17(2), pp. 1533-1536, 2007.

[5] W. Xian, Y. Yan, W. Yuan W, R. Pei.,T Coombs "Pulsed field magnetization of a HTS motor", IEEE Trans. App. Supercond., Vol. 21(3), pp. 1171-1174, 2011

[6] R. Alhasan, T.Lubin, B. Douine, Z.M. Adilov, J Lévêque, Test of an Original Superconducting Synchronous Machine Based on Magnetic Shielding, ", IEEE Trans. on Appl. Supercond, vol. 26 (4), 5204005, 2016.

[7] D. Zhou, M. Izumi, M. Miki, B. Felder, T. Ida, M. Kitano, "An overview of rotating machine systems with high-temperature bulk superconductors", Supercond. Sci. Tech., vol.25, 103001, 2012

[8] C. P. Bean, "Magnetization of high-field superconductors," Rev. Mod. Phys., pp.31-39, Jan. 1964.

[9] D.X. Chen, A. Sanchez, C. Navau, Y.H. Shi, D.A. Cardwell, "Critical current density of melt-grown single $\mathrm{YBaCuO}$ disks determined by ac susceptibility measurements," Supercond. Sci. Tech., vol. n²1, 085013, 6 pp., 2008.

[10] B. Douine, F. Sirois, J. Leveque, K. Berger, C.H. Bonnard, T.C. Hoang, S. Mezani, "A New Direct Magnetic Method for Determining $J c$ in Bulk 
Superconductors From Magnetic Field Diffusion Measurements," IEEE Trans. on Appl. Supercond., vol. 22 (3), 9001604, 2012.

[11] B. Douine, C.H. Bonnard, F. Sirois, K. Berger, A. Kameni, J. Leveque, “ Determination of $J c$ and n-value of HTS bulk by measurement and simulation of magnetic field penetration," IEEE Trans. on Appl. Supercond., vol. 25 (4), 8001008, 2015.

[12] B. Douine, K. Berger, C.H. Bonnard, F. Sirois, A. Kameni, J Lévêque, Improved Method for determining the n-value of HTS bulks, ", IEEE Trans. on Appl. Supercond., vol. 26 (3), 6800704, 2016.

[13] H. Yamasaki and Y. Mawatari, "Current-voltage characteristics and flux creep in melt-textured YBaCuO,” Supercond. Sci. Technol., vol. 13(2), pp. 202-208, Feb. 2000.

[14] P. Vanderbemden et al., "Behavior of bulk high-temperature superconductors of finite thickness subjected to crossed magnetic fields: Experiment and model," Phys. Rev. B, Condens. Matter Mater. Phys., vol. 75 (17), May 2007, Art. ID 174515.

[15] P. Bernstein, L. Colson, L. Dupont, and J. Noudem, "Investigation of the levitation force of field-cooled YBCO and MgB 2 disks as functions of temperature," Supercond. Sci. Technol., vol. 30, no. 6, p. 065007, 2017. 